\title{
Article \\ Polycyclic Aromatic Hydrocarbons and Polychlorinated Biphenyls in Seawater, Sediment and Biota of Neritic Ecosystems: Occurrence and Partition Study in Southern Ligurian Sea
}

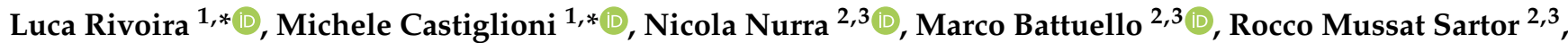 \\ Livio Favaro $^{2}$ (D) and Maria Concetta Bruzzoniti ${ }^{1, *(D)}$
}

check for updates

Citation: Rivoira, L.; Castiglioni, M.; Nurra, N.; Battuello, M.; Sartor, R.M.; Favaro, L.; Bruzzoniti, M.C.

Polycyclic Aromatic Hydrocarbons and Polychlorinated Biphenyls in Seawater, Sediment and Biota of Neritic Ecosystems: Occurrence and Partition Study in Southern Ligurian Sea. Appl. Sci. 2022, 12, 2564.

https://doi.org/10.3390/ app12052564

Academic Editors: Mauro Marini and Anna Annibaldi

Received: 30 December 2021

Accepted: 25 February 2022

Published: 1 March 2022

Publisher's Note: MDPI stays neutral with regard to jurisdictional claims in published maps and institutional affiliations.

Copyright: (C) 2022 by the authors. Licensee MDPI, Basel, Switzerland. This article is an open access article distributed under the terms and conditions of the Creative Commons Attribution (CC BY) license (https:// creativecommons.org/licenses/by/ $4.0 /)$
1 Department of Chemistry, Università degli Studi di Torino, Via Pietro Giuria 7, 10125 Torino, Italy

2 Department of Life Sciences and Systems Biology, Università degli Studi di Torino, Via Accademia Albertina 13, 10123 Torino, Italy; nicola.nurra@unito.it (N.N.); marco.battuello@unito.it (M.B.); rocco.mussat@unito.it (R.M.S.); livio.favaro@unito.it (L.F.)

3 Pelagosphera Marine Environmental Services Cooperative, Via U. Cosmo 17bis, 10131 Torino, Italy

* Correspondence: luca.rivoira@unito.it (L.R.); michele.castiglioni@unito.it (M.C.); mariaconcetta.bruzzoniti@unito.it (M.C.B.); Tel.: +39-011-670-5245 (L.R.); Fax: +39-011-230-5245 (L.R.)

\begin{abstract}
The Mediterranean Sea is subjected to a high anthropic pressure, which determines direct or indirect discharges of persistent organic pollutants deriving from intensive industrial activities. These compounds could easily enter and contaminate the whole marine compartment, with possible transfers (and contamination) among water, sediment and biota. Based on the above-mentioned assumptions, in this work we studied the presence of 16 polycyclic aromatic hydrocarbons (PAHs) and 14 dioxin and non-dioxin-like polychlorinated biphenyls (PCBs) in the neritic protected marine area of the Southern Ligurian Sea, affected by the impact of human activities. The study was focused on the possible partition of micropollutants within seawater, sediment and zooplankton. Results showed that both seasonal and anthropic causes strongly affect contaminant transfer behaviors, with summertime periods more impacted by PAH and PCB contamination. Regarding the PAH contamination, low molecular weight congeners were mainly detected in the target matrices, revealing concentrations up to $1 \mu \mathrm{g} / \mathrm{L}$ in seawater (anthracene), $250 \mu \mathrm{g} / \mathrm{Kg}$ in sediments (benzo[b]fluoranthene) and $2.3 \mathrm{mg} / \mathrm{Kg}$ in carnivorous copepods. Concerning PCBs, only few congeners were detected in the matrices studied. To better understand the occurrence of preferential bioaccumulation pathways in zooplankton, partition studies were also performed in several taxa (hyperbenthic Isopoda, holoplanktonic crustacean copepods and ichthyoplankton) through the calculation of BAF values, observing that both living and feeding habits could influence the bioaccumulation process.
\end{abstract}

Keywords: PAH; PCB; neritic environment; seawater; sediment; biota; partition; contamination

\section{Introduction}

Neritic environments are peculiar marine areas acting as interface between the atmosphere, the sea and the continental masses [1]. Due to their proximity to land and to sunlight infiltration, they are rich in nutrients and, consequently, in biologic activities, showing a remarkable biodiversity and biomass of algae, seagrasses and animal organisms inhabiting the coastal ecosystems.

Zooplankton, along with phytoplankton, representing the most abundant form of life in terms of biomass and biodiversity in neritic ecosystems, is comprised of heterotrophic microscopic, unicellular or multicellular organisms with size classes ranging from a few microns (picozooplankton) to a millimeter or more (mesozooplankton), such as the gelatinous zooplankton [2]. The marine zooplankton can be divided into two ecological categories: holoplankton, spending their entire lifecycle in the water column (e.g., crustaceans such as 
copepods and krill) and meroplankton, spending only the larval stages of their lifecycle as zooplankton, such as decapod crustaceans, echinoderms and fish larvae that, once they mature, adopt a benthic or nektonic lifestyle.

Taxa can be further distinguished depending on their typical living habits (permanently in the water column or diel vertical migration from benthos to sea surface such as hyperbenthic organisms e.g., Isopoda) and on their feeding habits and behavior (herbivorous, carnivorous and omnivorous).

Zooplankton plays a critical ecological role in marine food webs, both in the neritic and pelagic ecosystems, since it is involved in the conservation of energy from primary producers (phytoplankton) to higher trophic levels [3], in biogeochemistry cycles and in supporting the ocean's biological pump of carbon export. Hence, an alteration of this category, i.e., through chemical contaminations, can lead to disruptions up to the highest trophic levels.

Due to their peculiar conformation, neritic areas are strongly vulnerable to harmful effects of several anthropogenic pollutants derived from human activities, even when located far away from the pollution sources [4]. Such compounds could easily enter the whole marine ecosystem, with possible transfer (and contamination) along its main compartments, namely the water column, the sediment and the biota [5-7]. Transfer and contamination pathways mainly depend on the physicochemical properties of the pollutant molecules [8] or on the living habits of biota. Moreover, it is worth noting that the fate of pollutants is strongly influenced by the characteristics of the sea, such as water exchange capacity, as the enclosed or semi-enclosed basins (i.e., the Mediterranean Sea) are more susceptible to the accumulation of pollutants in marine sediments than open basins [9]. Among the organic micropollutants frequently detected in marine waters, are polycyclic aromatic hydrocarbons (PAHs) and polychlorinated biphenyls (PCBs) [10,11] PAHs represent pollutants of natural and anthropogenic origins (e.g., volcanic eruptions, combustion) while PCBs mainly derive from use in industrial activities (e.g., dielectric fluids, motor oils).

Seawater contamination from PAHs and PCBs derives from the not negligible impact of ports, industries and touristic activities located on coastal areas [12,13], as well as from wastewater treatment plants [14] and river effluents [15]. Atmospheric deposition presents an additional source of marine water contamination [16]. Since both PAHs and PCBs are mutagenic/carcinogenic recalcitrant pollutants [17], there are serious concerns regarding their presence in the environment [18-20], particularly in neritic compartments, and also with consideration of their tendency to partition between water and sediments and from water and sediments to biota, due to their high octanol/water partition coefficients ( $\log \mathrm{K}_{\mathrm{OW}}$ ranging from 2.96 to 5.60 for PAHs and from 5.41 to 7.83 for PCBs) [21].

In Europe, the environmental status of water compartments (including neritic areas) is regulated by the 2013/39/EU directive [22], adopted in Italy by the Legislative Decree 172/2015 [23], in which a list of priority substances (including selected PAHs and PCBs compounds) to be monitored in water, sediments and biota is reported. For individual congeners of PAHs, Environmental Quality Standards (EQS) are fixed for water, sediments and biota, defining annual average values (AA-EQS) and maximum allowable concentrations (MAC-EQS). Conversely, AA-EQS for PCBs in biota refer only to dioxin-like congeners, while with regards to sediments the same dioxin-like compounds, together with other eight congeners, are considered. It should be highlighted that, to date, the limits for PCBs in marine waters remain unregulated.

Due to the strategic importance of coastal areas in the marine ecosystems, as previously presented, several studies investigated the contamination from PAHs and PCBs in neritic environments, as well as their partition between water columns, sediments and biota [24-26]. Within this literature, an extensive bibliography is dedicated to the Mediterranean Sea which, due to its morphological peculiarities, is strongly subjected to anthropic impact. In particular, studies on PAH and PCB contamination of the Venice Lagoon [27], Tyrrhenian Sea [28], and Ionian Sea [29] are reported. On the other hand, few studies 
were focused on Ligurian Sea [30-32], even though its pollution causes serious concern, due to intense anthropic activities (e.g., ports, industries, tourism, etc.) [32]. Furthermore, studies investigating the possible distribution pathways of PAHs and PCBs within neritic compartments of Ligurian Sea are, as far as we know, absent thus far, despite the natural (marine protected area) and economic (shipping, industries, harbors) strategical importance of this area.

Based on the above considerations, the aim of this work is the study of the contamination of PAHs and PCBs (both dioxin and non-dioxin-like congeners) in the neritic environment of the Southern Ligurian Sea, which hosts a protected marine area called "Cetacean Sanctuary". The study focuses comprehensively on the possible partition of micropollutants among the environmental compartments of the marine ecosystem (seawater, sediment and zooplankton), and on the factors that could influences these transfer behaviors (i.e., seasonality). With this aim, analytical protocols for the extraction and quantitation of PAHs and PCBs from seawater, sediment and zooplankton were developed and validated. Furthermore, to better understand the presence of preferential pathways of bioaccumulation in zooplankton, partition studies were also carried out in four taxa, chosen on the basis of dietary habits (herbivorous or carnivorous) and living environment: hyperbenthic Isopoda, herbivores and carnivorous holoplanktonic crustacean copepods and fish larvae (ichthyoplankton). To the best of our knowledge, this study is the first to describe the partition of PAHs and PCBs in this protected area of the Ligurian Sea, with unique natural characteristics, providing insights on the contamination of the whole bioma.

\section{Materials and Methods}

\subsection{Sampling Area and Sample Pre-Treatments}

Waters, sediments and biota were sampled in the Ligurian Sea, in an offshore area (12.5 nautical miles off the Italian coast), above the continental shelf, at the border with Northern Tyrrhenian Sea, the same study area of previous research [5] and included the following stations: (i) $43^{\circ} 29^{\prime} 40^{\prime \prime} \mathrm{N}-10^{\circ} 01^{\prime} 45^{\prime \prime} \mathrm{E}$, (ii) $43^{\circ} 28^{\prime} 10^{\prime \prime} \mathrm{N}, 10^{\circ} 01^{\prime} 55^{\prime \prime} \mathrm{E}$ and (iii) $43^{\circ} 27^{\prime} 10^{\prime \prime} \mathrm{N}, 10^{\circ} 03^{\prime} 00^{\prime \prime} \mathrm{E}$ (see Figure S1 of Supplementary Material). The area was considered of great interest for several reasons. In fact, it is characterized by one of the highest levels of shipping in the Mediterranean basin; moreover, a strong anthropogenic influence and impact are present due to several commercial, industrial and harbor activities. The investigated area hosts the "Cetacean Sanctuary", an extensive marine protected area where the number of cetaceans is at least double that of any other part of the Mediterranean. Finally, the area is subjected to a high dynamic water current equilibrium, since both perpetual and seasonal currents influence the possible dispersion and partition of micropollutants originating from the highly developed coastline of Italy.

Two samplings were carried out for both water column and marine biota during summer 2017 and winter 2018, in order to assess the possible contribution of seasonality. For the sediment, a single sample was collected in summer 2017, due to the low effect of the seasonality on the circalittoral mud sediments.

Sampling methods were performed as follows: (i) water column, $5 \mathrm{~L}$ collection for each sampling using a PVC Niskin bottle water sampler (collected at $5 \mathrm{~m}$ depth). Subsequently, the samples were filtered via qualitative paper and refrigerated until analysis; (ii) sediments, sampled using a $18 \mathrm{~L}$ Van Veen grab sampler on the seabed at $110 \mathrm{~m}$ depth. Moisture evaporation (at $60{ }^{\circ} \mathrm{C}$ for $12 \mathrm{~h}$ ) was performed prior to micropollutant extraction and analysis; (iii) marine biota (mesozooplankton and ichthyoplankton) was collected in a surface haul, using a WP-2 standard net $(200 \mu \mathrm{m}$ mesh size and diameter $57 \mathrm{~cm})$. The horizontal sampling time was approximately $15 \mathrm{~min}$ ( 2 knots vessel cruising speed). The net was fitted with a flow-meter (KC Denmark model 23.090) to measure volume of water filtered. After collection, each zooplankton sample was washed, on board first, with filtered seawater from the sampling site, in order to remove terrigenous or inorganic particles, and hence washed with distilled water. After the washing procedure, samples were immediately fixed in $70 \%$ ethanol and seawater and stored in the dark. 
In the laboratory, a qualitative-quantitative analysis of the marine biota was performed with a Leica stereomicroscope and microscope, which allowed the identification and regrouping of the following four taxa: hyperbenthic Isopoda, holoplanktonic crustaceans' copepods both herbivores and carnivorous and fish larvae (ichthyoplankton). Samples were dried at $80{ }^{\circ} \mathrm{C}$ for $12 \mathrm{~h}$ before extraction and analysis.

\subsection{Reagents}

Acetone $\geq 99.8 \%$, dichloromethane $\geq 99.9 \%$, 2-propanol $\geq 99.8 \%$, methanol $\geq 99.9 \%$, sodium hydroxide $\geq 98.0 \%$, sulfuric acid 96-97\%, magnesium sulphate anhydrous $\geq 99.5 \%$ and $\mathrm{NaCl} \geq 99.5 \%$ were obtained from Honeywell Riedel-de-Haën, Fisher Scientific Italia, Rodano, MI (Italy). Cyclohexane 99.5\% and dichloromethane were obtained from VWR International (Radnor, PA, USA).

High-purity water $\left(18.2 \mathrm{M} \Omega \mathrm{cm}\right.$ resistivity at $\left.25^{\circ} \mathrm{C}\right)$, produced by an Elix-Milli $\mathrm{Q}$ Academic system (Millipore-Billerica, MA, USA) was used.

The d-SPE sorbent used was Primary Secondary Amine (PSA) from Agilent Technologies (Santa Clara, CA, USA).

The 16 PAHs studied, i.e., naphthalene ( $\mathrm{NaPh})$, acenaphthylene (AcPY), acenaphthene (AcPh), fluorene (Flu), phenanthrene (Phe), anthracene (Ant), fluoranthene (Flth), pyrene (Pyr), benzo[a]anthracene $(\mathrm{BaA})$, chrysene $(\mathrm{Chr})$, benzo[b]fluoranthene $(\mathrm{BbFl})$, benzo[k]fluoranthene (BkFl), benzo[a]pyrene (BaP), indeno[1,2,3-cd]pyrene (Ind), dibenzo[a,h]anthracene (DBA) and benzo[ghi]perylene (BP), were the compounds listed by the United States Environmental Protection Agency (US-EPA) and were purchased from Wellington Laboratories (Guelph, ON, Canada).

The 14 PCBs studied were purchased from Chemical Research 2000 (Rome, Italy). They were chosen according to the results of the main monitoring campaigns and included 3,3'-dichlorobiphenyl (PCB 11), 4,4'-dichlorobiphenyl (PCB 15), 2,4,4'-trichlorobiphenyl (PCB 28), 2,2' ,5,5' -tetrachlorobiphenyl (PCB 52), 2,2', 4,5,5'-pentachlorobiphenyl (PCB 101), 2,2' 3,4, $4^{\prime}, 5$-hexachlorobiphenyl (PCB 138), 2,2' ,4, 4' ,5,5'-hexachlorobiphenyl (PCB 153) and $2,2^{\prime}, 3,4,4^{\prime}, 5,5^{\prime}$-heptachlorobiphenyl (PCB 180). Furthermore, the following dioxin-like PCBs were included 3,4,4', 5-tetrachlorobiphenyl (PCB 81), 2,3', 4, 4',5-pentachlorobiphenyl (PCB 118), 2' ,3,4,4', 5-penta-chlorobiphenyl (PCB 123), and 2, $3^{\prime}, 4,4^{\prime}, 5,5^{\prime}$-hexachlorobiphenyl

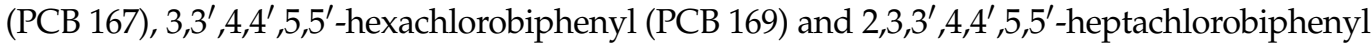
(PCB 189)

Isotope labelled compounds for PAHs (5 mg/L) and for PCBs (2 mg/L), both purchased from Wellington Laboratories, were employed as internal standards and surrogates to obtain calibration curves and to calculate extraction recoveries. The deuterated PAH surrogate solution included the following compounds: benzo[a]anthracene-d12 (BaA-d12), chrisene-d12 (Chr-d12), benzo[b]fluoranthene-d12 (BbFl-d12), benzo[k]fluoranthene-d12 (BkFl-d12), benzo[a]pyrene-d12 (BaP-d12), indeno[1,2,3-cd]pyrene-d12 (Ind-d12), dibenzoanthracene-d14 (DBA-d14), benzoperylene-d12 (BP-d12). The ${ }^{13} \mathrm{C}-\mathrm{PCB}$ surrogate solution included the following congeners: ${ }^{13} \mathrm{C}_{12}$-PCB28, ${ }^{13} \mathrm{C}_{12}$-PCB52, ${ }^{13} \mathrm{C}_{12}-\mathrm{PCB} 118$, ${ }^{13} \mathrm{C}_{12}$-PCB153, and ${ }^{13} \mathrm{C}_{12}$-PCB180. ${ }^{2} \mathrm{H}$-anthracene and ${ }^{13} \mathrm{C}_{12}$-PCB70 were used as internal standards.

\subsection{Chromatographic Analysis}

PAHs and PCBs, extracted from neritic matrices as detailed in the following paragraphs, were analyzed by gas chromatography coupled with mass spectrometry (GC-MS) using an Agilent 6980 series gas chromatograph and an Agilent 5973 Network MS detector controlled by Agilent ChemStation software. The gas chromatograph was provided with an autosampler of the Agilent 7683 Series.

The GC column was a (5\%-Phenyl)-methylpolysiloxane column (DB-5 ms, $30 \mathrm{~m} \times 0.25 \mathrm{~mm} \times 25 \mu \mathrm{m}$; Agilent). Helium was employed as gas carrier $(1 \mathrm{~mL} / \mathrm{min})$. MS detection was performed in Single Ion Monitoring (SIM) mode at proper $m / z$ ratio $(m / z$ ratio available upon request). Injections $(2 \mu \mathrm{L})$ were performed by the pulsed splitless 
mode (pressure at 40 psi for $2.5 \mathrm{~min}$, injector temperature $280^{\circ} \mathrm{C}$ ). The oven ramp for $\mathrm{CH}_{3} \mathrm{CN}$ and $\mathrm{CH}_{2} \mathrm{Cl}_{2}$ was set as follows: starting temperature: $80^{\circ} \mathrm{C}$, hold for $2 \mathrm{~min}$; ramp to $176{ }^{\circ} \mathrm{C}, 12{ }^{\circ} \mathrm{C} / \mathrm{min}$ rate; ramp to $196{ }^{\circ} \mathrm{C}, 5^{\circ} \mathrm{C} / \mathrm{min}$ rate, hold for $3 \mathrm{~min}$; ramp to $224^{\circ} \mathrm{C}$, $12{ }^{\circ} \mathrm{C} / \mathrm{min}$ rate; ramp to $244^{\circ} \mathrm{C}, 12^{\circ} \mathrm{C} / \mathrm{min}$ rate, hold for $3 \mathrm{~min}$; ramp to $270{ }^{\circ} \mathrm{C}, 7{ }^{\circ} \mathrm{C} / \mathrm{min}$ rate, hold for $3 \mathrm{~min}$; final ramp to $300{ }^{\circ} \mathrm{C}, 5^{\circ} \mathrm{C} / \mathrm{min}$, hold for $10 \mathrm{~min}$ to completely clean and restore the GC column. The complete separation of the 13 PAHs and 14 PCBs was obtained within $49 \mathrm{~min}$.

\subsection{Extraction of PAHs and PCBs from Neritic Matrices}

All the extraction procedures used for water, sediment and biota were specifically optimized for this study and are hereafter detailed. Aliquots of all the matrixes were extracted in triplicate. Blank samples were run in parallel to evaluate possible ambient contamination.

\subsubsection{Water Column}

Extraction was performed via solid-phase extraction (SPE) using an SPE Vacuum manifold and a polymeric reversed-phase (RP) cartridge (STRATA-XL-100 $\mu \mathrm{m}$; Phenomenex, Torrance, CA, USA), The cartridge was conditioned (20 psi) with $5 \mathrm{~mL} \mathrm{CH}_{2} \mathrm{Cl}_{2}, 5 \mathrm{~mL}$ 2-propanol, and $5 \mathrm{~mL} \mathrm{H}_{2} \mathrm{O}$. Then, $200 \mathrm{~mL}$ water sample added with $20 \mathrm{~mL}$ 2-propanol was loaded (50 psi) on the SPE cartridge. The water sample container was subsequently washed with $20 \mathrm{~mL}$ 2-propanol-water solution $(10+90, v / v)$. After loading, the cartridge was washed (20 psi) with $5 \mathrm{~mL} \mathrm{H}_{2} \mathrm{O}$, and $5 \mathrm{~mL}$ 2-propanol-water solution $(85+15, v / v)$. The cartridge was dried for $10 \mathrm{~min}$, and the analytes were finally eluted with two aliquots of $1.0 \mathrm{~mL} \mathrm{CH} \mathrm{Cl}_{2}$. The eluted extract was spiked with the internal standard solution of PAHs and PCBs to achieve a final concentration of $5 \mu \mathrm{g} / \mathrm{L}$ and injected for GC-MS analysis. To evaluate the extraction recoveries of PAHs and PCBs, before extraction, the water samples were spiked with surrogates (as detailed in "Reagents" section) to achieve a final concentration of $2 \mu \mathrm{g} / \mathrm{L}$.

\subsubsection{Sediment}

Sediments were extracted through a QuEChERS procedure. In detail, $5 \mathrm{~g}$ sediment (previously spiked with surrogates to achieve a final concentration of $2 \mu \mathrm{g} / \mathrm{L}$ in the extract solvent) were extracted in $10 \mathrm{~mL} \mathrm{CH}_{2} \mathrm{Cl}_{2}$ with the addition of $1 \mathrm{~g} \mathrm{NaCl}$ and $0.4 \mathrm{~g} \mathrm{MgSO}_{4}$. The extraction mixture was shaken for $5 \mathrm{~min}$ and subsequently centrifuged for $10 \mathrm{~min}$ $(1534 \times g)$. For the d-SPE purification step, $6 \mathrm{~mL}$ of the supernatant was transferred into a $15 \mathrm{~mL}$ tube containing $50 \mathrm{mg}$ of PSA and $150 \mathrm{mg} \mathrm{MgSO}$. The mixture was again shaken for $5 \mathrm{~min}$ and centrifuged for $10 \mathrm{~min}(7871 \times \mathrm{g})$. A $2 \mathrm{~mL}$ aliquot of the supernatant was spiked with internal standards to achieve a final concentration of $5 \mu \mathrm{g} / \mathrm{L}$ and injected for GCMS analysis.

\subsubsection{Biota}

Each taxon was separately extracted to study possible partition pathways. A total of $100 \mathrm{mg}$ of each taxon were weighted inside a $50 \mathrm{~mL}$ tube and spiked with surrogates to achieve a final concentration of $2 \mu \mathrm{g} / \mathrm{L}$ in the extract solvent. Subsequently, $16 \mathrm{~mL}$ $4 \mathrm{M} \mathrm{NaOH}, 4 \mathrm{~mL}$ methanol and $10 \mathrm{~mL} \mathrm{CH} \mathrm{Cl}_{2}$ were added. The extraction mixture was shaken for $1 \mathrm{~min}$, sonicated for $15 \mathrm{~min}$ and refrigerated at $4{ }^{\circ} \mathrm{C}$ for $2 \mathrm{~h}$. Finally, the tube was centrifuged for $10 \mathrm{~min}(7871 \times g)$ and a $2 \mathrm{~mL}$ aliquot of the supernatant was spiked with internal standards to achieve a final concentration of $5 \mu \mathrm{g} / \mathrm{L}$ and injected for GCMS analysis.

\subsection{Recovery Evaluation}

To evaluate the apparent recoveries of each extraction method developed, each sample was spiked, before extraction, with surrogate solutions of PAHs and PCBs to achieve a final concentration of $2 \mu \mathrm{g} / \mathrm{L}\left(C_{S}\right)$. After extraction, the concentrations were calculated by using 
an external standard calibration curve prepared in dichloromethane and the extraction yield $(E \%)$ was calculated according to the following equation:

$$
E \%=\frac{C_{e}}{C_{s}} * 100
$$

where $C_{e}$ is the calculated concentration of the surrogate after extraction expressed as $\mu \mathrm{g} / \mathrm{L}$.

\subsection{Validation of Analytical Protocols}

The protocols developed for the extraction and quantitation of PAHs and PCBs from water, sediment and biota were validated through the evaluation of linearity, limits of detection (MDL) and quantitation (MQL). Linearity was evaluated over ten concentration levels, within a concentration range included between $0.87 \mu \mathrm{g} / \mathrm{L}$ and $14 \mu \mathrm{g} / \mathrm{L}$ for PAHs and between $0.42 \mu \mathrm{g} / \mathrm{L}$ and $6.75 \mu \mathrm{g} / \mathrm{L}$ for PCBs in $\mathrm{CH}_{2} \mathrm{Cl}_{2}$. The values of MDL and MQL for the 30 target compounds were calculated by means of the response error and the slope of the calibration curve, using the expression $\mathrm{MDL}=3.3 \mathrm{Sy} / \mathrm{m}$, and $\mathrm{MQL}=10 \mathrm{Sy} / \mathrm{m}$, where Sy $=$ response error; $\mathrm{m}=$ slope of the calibration.

\subsection{Bioaccumulation Factor}

Bioaccumulation factor (BAF) is defined as the ratio of the concentration of a micropollutant in an organism to the concentration of the same compound in water [33]. Logarithmic BAFs were individually estimated for all the analytes detected both in biota matrices, as follows:

$$
\log B A F=\log \frac{C_{\text {biota }}}{C_{\text {water }}}
$$

Finally, for both herbivorous and carnivorous zooplankton, the average of $\log B A F$ values was calculated and results were compared and discussed to understand possible effects of feeding habits in the bioaccumulation process.

\section{Results and Discussion}

\subsection{Optimization of Analytical Protocols}

To verify the effectiveness of the analytical methods developed for the analysis of PAH and PCB occurrence and partition in water, sediment and biota, extraction yields, methods detection (MDL) and quantitation limits (MQL) were assessed.

For each matrix, the extraction recoveries were determined using surrogates and were identified in the following ranges, water: from 52\% (Ind-d12) to 88\% (BaA-d12) for PAHs and from $54 \%\left({ }^{13} \mathrm{C}_{12}\right.$-PCB118) to $77 \%\left({ }^{13} \mathrm{C}_{12}\right.$-PCB28) for PCBs, with RSD\% lower than $10 \%$ for all the analytes; sediment: from 54\% (Ind-d12) to 96\% (BaA-d12) for PAHs and from $56 \%$ (13C12-PCB52) to 86\% (13C12-PCB28) for PCBs, with RSD\% lower than 7\% for all the analytes; biota: from $80 \%$ (DBA-d14) to $93 \%$ (BaA-d12) for PAHs and from $79 \%\left({ }^{13} \mathrm{C}_{12^{-}}\right.$ PCB28) to $93 \%\left({ }^{13} \mathrm{C}_{12}\right.$-PCB118) for PCBs, with $\mathrm{RSD} \%$ lower than $8 \%$ for all the analytes. Extraction yields are reported in Figures S2-S4 of Supplementary Materials for both PAHs and PCBs in the three matrices.

The results here obtained for all the matrices are in the same range (or higher) than other studies devoted to the analysis of PAHs and PCBs in marine compartments [25,34,35]. Differently from the procedures typically applied to sediments, the proposed QuEChERS protocol is green and sustainable since it does not require high volumes of organic solvents. Furthermore, the method does not require a final evaporation step (which increases the risk of losing target analytes) [25].

MDL and MQL for water, sediment and biota are reported in Tables S1 and S2, together with regulation limits (if present). MQL were in the following ranges, water: from $4.6 \mathrm{ng} / \mathrm{L}$ (NaPh) to $27 \mathrm{ng} / \mathrm{L}$ (DBA) for PAHs and from $6 \mathrm{ng} / \mathrm{L}$ (PCB11) to $32 \mathrm{ng} / \mathrm{L}$ (PCB123) for PCBs; sediment: from $3 \mu \mathrm{g} / \mathrm{Kg}$ (DBA) to $20 \mu \mathrm{g} / \mathrm{Kg}$ (AcPY) for PAHs and from $1 \mu \mathrm{g} / \mathrm{Kg}$ (PCB153) to $3 \mu \mathrm{g} / \mathrm{Kg}$ (PCB123) for PCBs; biota: from $10 \mu \mathrm{g} / \mathrm{Kg}$ (BaP and Ind) to $21 \mu \mathrm{g} / \mathrm{Kg}$ 
(BP) for PAHs and from $15 \mu \mathrm{g} / \mathrm{Kg}$ (PCB138) to $35 \mu \mathrm{g} / \mathrm{Kg}$ (PCB189) for PCBs. These values fully satisfy the limits fixed by the Italian and European regulations (previously described).

\subsection{Chemical Characterization of Seawater}

PAHs detected in seawater (both in summer and winter samples) are summarized in Figure 1.

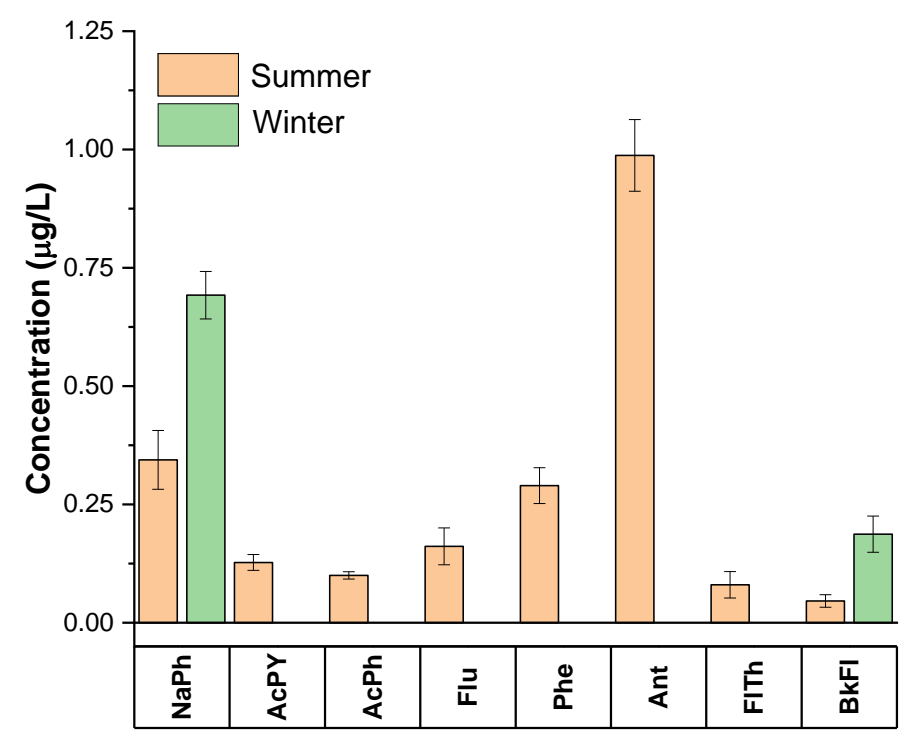

Figure 1. Concentration of PAHs detected in seawater samples, both in summer (orange) and winter (green) sampling. Analytical conditions are detailed in the Experimental section.

It is interesting to observe that PAHs with a higher number of aromatic rings (i.e., $\mathrm{BbFl}, \mathrm{BaP}, \mathrm{DBA}, \mathrm{BP}$ and Ind) were not detected in seawater, regardless of the season, in accordance with their higher hydrophobicity behavior (and hence lower solubility in water).

In addition, an inter-seasonal variability of PAH concentrations (among summer and winter sampling campaigns) was also clearly present for all the detected analytes. Indeed, a higher number of congeners was detected in summer (8), rather than in winter (2), with a total PAH concentration about three times higher in summer than winter $(2.2 \mu \mathrm{g} / \mathrm{L}$ and $0.8 \mu \mathrm{g} / \mathrm{L}$, respectively).

To explain these differences, both climatological and anthropogenic effects should be considered. To elucidate, one of the main aspects to consider is the seasonal variation of thermocline. Thermocline refers to the water layer below the surface, characterized by a massive temperature gradient which decreases up to $4{ }^{\circ} \mathrm{C}$ (or lower for deep waters). During summertime, surface waters increase in temperature while the deeper waters remain cold. Stratification causes rapid vertical changes in the density of water, which largely prevents the mixing of the water column [36]. This phenomenon could affect the sinking and the accumulation of micropollutants [37]. Conversely, during winter, temperatures of surface water can undergo those of deeper layers, which tends to rise due to its lower density (homothermic conditions). Consequently, the movement of water masses promotes a mixing and, therefore, a diffusion of dissolved compounds, such as pollutants, thus justifying their lower concentrations.

In addition to the thermocline effect, the higher concentration of PAHs in the summer season could be addressed to the effects of the Northern current, the northern part of the cyclonic surface circulation of the North-Western Mediterranean Sea. Indeed, the Northern current exhibits its weakest intensities during summertime [38], thus promoting a possible accumulation of land and air derived pollutants, while during winter its higher intensities boosts their dispersion into the sea waters. 
Finally, the intense touristic activities that characterize the Ligurian Sea during summertime (with private boat traffic, cruises, etc.) with respect to winter, could act as a possible source of PAHs, which can be released by thermic engines. Evidence of the effects of maritime traffic on the increment of PAH contamination were also investigated elsewhere [39]. In addition, the origin of PAHs (evaluated by studying the ration between congeners [40]) confirmed this hypothesis. In fact, both the ratio between the concentration of low (NaPh, AcPh, AcPY, Flu) and high molecular weight (Phe, Ant, FlTh, BkFl) PAHs (0.92) and the ratio between phenanthrene and anthracene (0.30) are lower than 1, thus suggesting a dominant pyrogenic origin of the detected PAHs (i.e., transport activities, use of petroleum derived products, accumulation of small emissions of gasoline, engine oils, incomplete combustion of organic substances) [41,42].

It should be noted that PAH concentrations detected in sea water within this study were in the same level of other Mediterranean areas [43], with a pollution classification from moderate to high, according to the indications proposed by Baumard and colleagues [44]. Concerning regulation limits, benzo[k]fluoranthene was the only congener detected among the compounds included in the regulated list, with an average concentration of $45 \mathrm{ng} / \mathrm{L}$, which exceeds the maximum allowable concentrations (17 ng/L) [22].

Concerning PCBs, only congeners 15 and 138 were detected, with concentrations below the quantitation limits.

\subsection{Chemical Characterization of Sediment}

As discussed in the previous section, the presence of PAHs and PCBs was observed in seawater. Hence, the analysis of sediment belonging to the same sea area is justified to assess whether a partition took place from the waters. Results are reported in Figure 2.

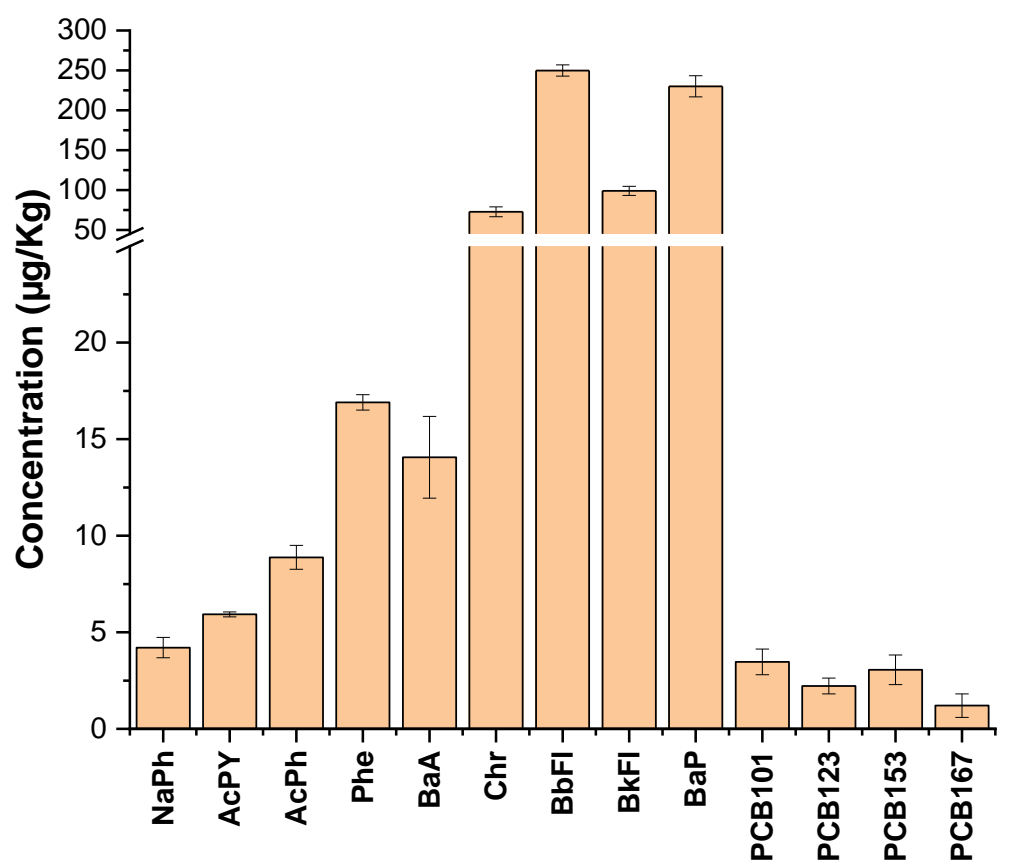

Figure 2. Concentration of PAHs and PCBs detected in sediment. Analytical conditions are detailed in the Experimental section.

Results showed that, as for seawater, PAHs containing the highest number of aromatic rings (i.e., DBA, BP and Ind) were not present (Figure 2), except for $\mathrm{BbFl}$ and $\mathrm{BaP}$ that were not previously detected in the water column.

The total amount of PAHs in sediment was assessed to reach about $700 \mu \mathrm{g} / \mathrm{Kg}$, with most of the contribution ascribed to higher molecular weight compounds (i.e., BaA $(14 \mu \mathrm{g} / \mathrm{Kg}), \mathrm{Chr}(73 \mu \mathrm{g} / \mathrm{kg}), \mathrm{BbFl}(250 \mu \mathrm{g} / \mathrm{Kg}), \mathrm{BkFl}(99 \mu \mathrm{g} / \mathrm{Kg})$ and BaP $(230 \mu \mathrm{g} / \mathrm{Kg}))$. The 
concentration of these compounds accounted for almost $95 \%$ of the total PAH concentration. Upon comparing these latter results (Figure 2) with those previously presented for the water column (Figure 1), it was observed that the contribution of the compounds with higher molecular weight to the total PAH content measured higher in sediment rather than in water. Such differences remain in good agreement with the physicochemical properties of PAHs and may be ascribed to the different partitioning attitudes of the individual compounds. Indeed, the higher the molecular weight, the higher the octanol-water partition coefficients, thus enhancing the sorption on the organic matter present in the sediment [45]. In addition, it should be mentioned that neritic areas are highly subjected to sediment resuspension [46] which causes organic matter to rise temporarily in water and, hence, favoring the sorption of PAHs dissolved in water.

As for seawater, the ratios between PAH congeners (see "Chemical characterization of seawater" section) confirm a pyrogenic origin of the PAHs detected in sediment $(\Sigma$ LowPAHs $/ \Sigma$ HighPAHs $=0.04$ and $\mathrm{BaP} /(\mathrm{BaP}+\mathrm{Chr})=0.76)$. Hence, detected contamination should be tentatively ascribed to industrial activities, as well as to maritime transport.

Concerning PCBs, detected concentrations were about two orders of magnitude lower in comparison to PAHs (Figure 2), ranging from $1.2 \mu \mathrm{g} / \mathrm{Kg}$ (PCB167) to $3.3 \mu \mathrm{g} / \mathrm{Kg}$ (PCB101). Even if no congeners were detected in seawater, their presence in sediment at quantifiable concentrations could be ascribed to the sorption properties of sediment towards microorganic pollutants, as described for PAHs [47]. A similar behavior was also confirmed by studies performed in other marine areas, where PCBs were detected at fractions of $\mathrm{ng} / \mathrm{L}$ in water and at $\mu \mathrm{g} / \mathrm{Kg}$ in sediments [48].

It should be mentioned that PAH concentrations detected in sediment exceeded the limit imposed by Italian and European regulations for BbFl (limit: $40 \mu \mathrm{g} / \mathrm{Kg}$ ), BkFl (limit: $40 \mu \mathrm{g} / \mathrm{Kg}$ ) and BaP (limit: $40 \mu \mathrm{g} / \mathrm{Kg}$ ). As for the sum of PCB congeners $(10.5 \mu \mathrm{g} / \mathrm{Kg}$ ), this value partially exceeded the limit of $8 \mu \mathrm{g} / \mathrm{Kg}$. However, similar values are not uncommonly found in the Mediterranean sea, due to the high impact of anthropic activities, as shown by other studies $[44,49]$.

\subsection{Chemical Characterization of Biota and Partition Studies}

PAH and PCB contamination was measured in four zooplankton taxa, namely hyperbenthic Isopoda, herbivores and carnivorous holoplanktonic crustaceans copepods and fish larvae-ichthyoplankton, previously sorted after summer and winter sampling campaigns. The results obtained are hereafter discussed.

\subsubsection{Copepods}

Regarding crustaceans copepods, results are summarized in Figure 3A (herbivorous) and Figure 3B (carnivorous).

Data showed that PAHs were detected in both taxa at higher concentrations than PCBs, with a total concentration from $270 \mu \mathrm{g} / \mathrm{Kg}$ (winter) to $1.3 \mathrm{mg} / \mathrm{Kg}$ (summer) for PAHs witn respect to $43 \mu \mathrm{g} / \mathrm{Kg}$ for PCBs (detected only in summer campaign) for herbivorous copepods. For carnivorous copepods, PAHs concentrations from $230 \mu \mathrm{g} / \mathrm{Kg}$ (winter) to $4.3 \mathrm{mg} / \mathrm{Kg}$ (summer) were measured, with no detection of PCBs. The measured concentrations are in the same range of those obtained by Cailleaud and colleagues in estuarine water (in which seasonal variability was also assessed) [50] or by Tiano and colleagues in Marseille Bay (Mediterranean Sea) [51].

Since copepods tend to spend their entire lives mostly in the water column [52], comparison with PAH and PCB contamination in this matrix seems to be fully justified. Concerning PAHs, the same congeners ( $\mathrm{NaPh}, \mathrm{AcPY}, \mathrm{Flu}, \mathrm{Phe}$, Ant, FlTh and $\mathrm{BkFl}$ ) detected in seawater were detected in both herbivorous and carnivorous copepods (Figure 1 vs. Figure 3A,B). Furthermore, the same seasonal trend observed for water (i.e., higher number of congeners and concentrations in summer sampling, rather than in winter) was observed for copepods. This behavior suggests that a possible transfer of micropollutants from water to copepods had occurred. To support this hypothesis, it is important to note that Phe 
and Ant, which were found to be almost the most abundant PAH compounds in water, confirmed this trend also in herbivorous copepods.

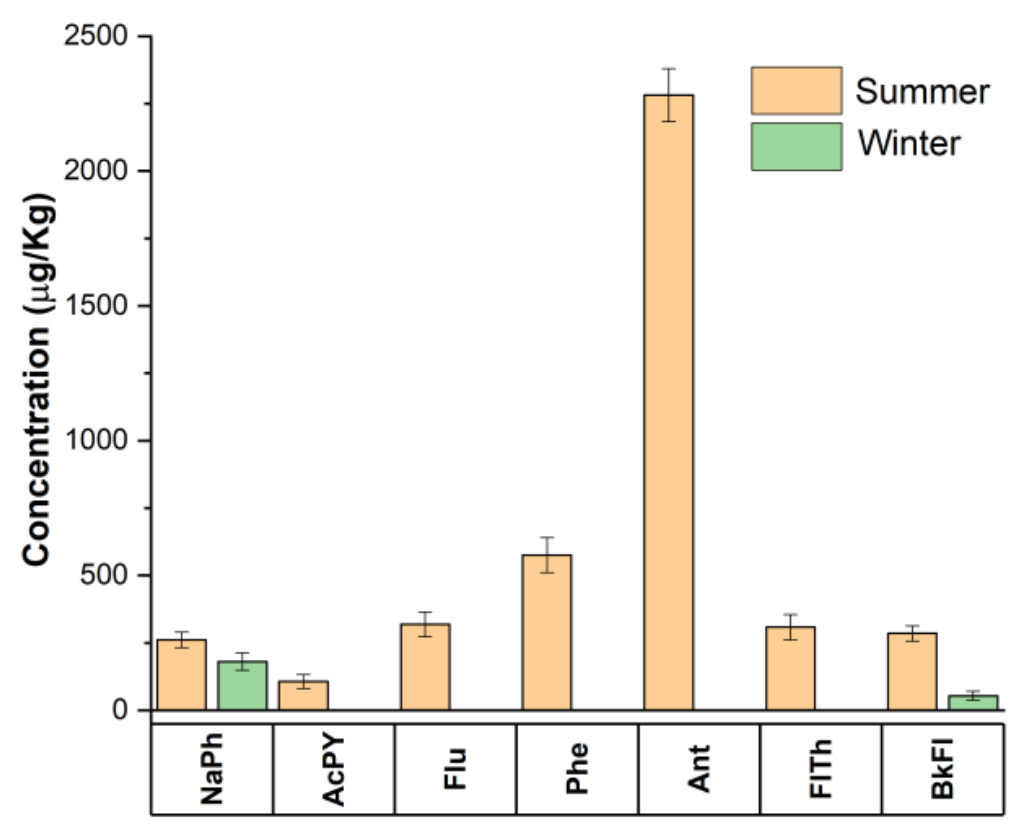

(A)

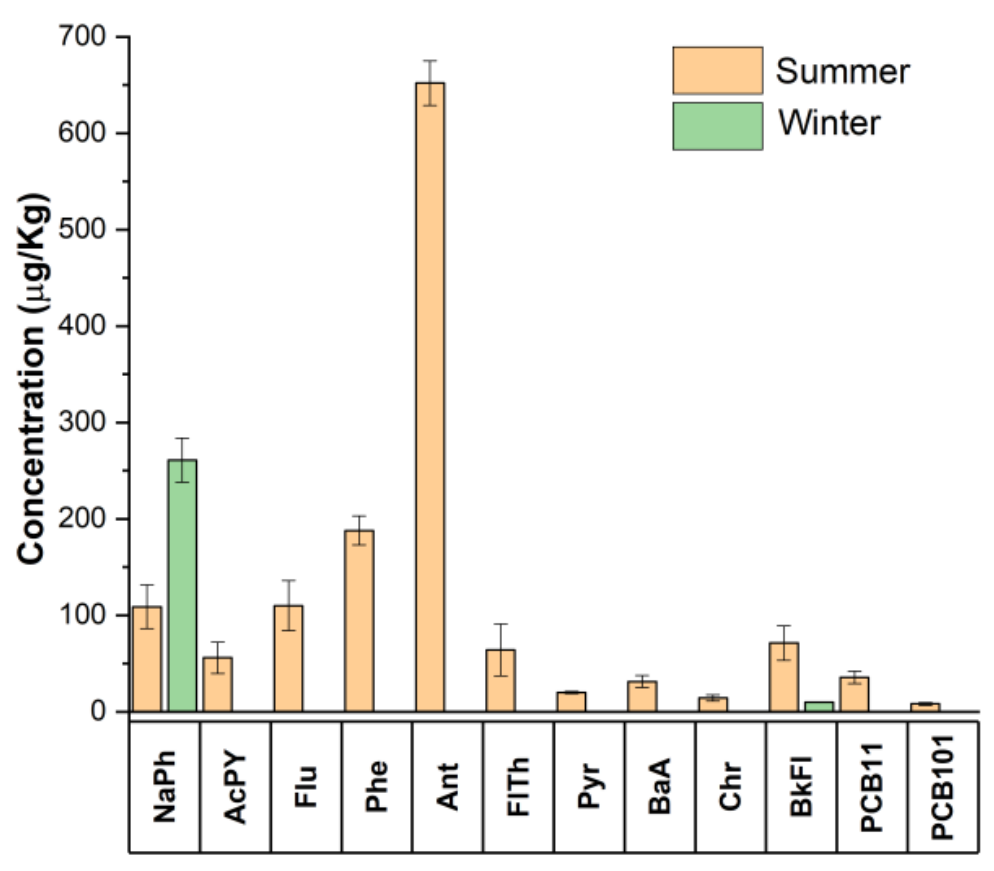

(B)

Figure 3. Concentration of PAHs and PCBs detected in herbivorous (A) and carnivorous (B) copepods. Both summer (orange) and winter (green) sampling are reported. Analytical conditions are detailed in the Experimental section.

In contrast, Pyr, BaA and Chr, which were detected in the herbivorous copepods, were not present in carnivorous copepods and in seawater. The presence of these congeners could be explained taking into account feeding habits, since it was recently demonstrated that 
herbivorous copepods could be deceived in their feeding by microplastics and nanoplastics, upon which algae and phytoplankton grow [53]. Such micropolymers have been shown to adsorb organic and inorganic pollutants (such as PAHs and PCBs) [54], thus suggesting that they could be an additional source of PAH congeners once ingested by organisms [55].

Moreover, the same hypothesis could be formulated to explain the detection of PCB11 and 101 in herbivorous copepods (Figure 3A), which were not previously detected in the water column and that were below detection limits in carnivorous organisms. The observed PCB contamination does not exceed limits imposed by European and Italian regulation, since both congeners are not dioxin-like and limits on biota are referred only to dioxin-like compounds.

\subsubsection{Hyperbenthic Isopoda}

PAH and PCB contamination detected in hyperbenthic Isopoda was observed to be almost absent, apart from $\mathrm{NaPh}$, detected at $280 \pm 20 \mu \mathrm{g} / \mathrm{Kg}$, and PCB101, detected at $140 \mu \mathrm{g} / \mathrm{Kg}$ (summer-winter average concentrations). RSD \% between summer and winter measured below $8 \%$ for both analytes, indicating that, for this taxon, a seasonal variance is not present.

Moreover, It is interesting to note that PCB101, the most abundant pollutant detected in sediment (see "Chemical characterization of sediment" paragraph), is the only congener detected in hyperbenthic Isopoda. Since hyperbenthic Isopoda was assessed to live half of its life in contact with sediment [56], a possible transfer could not be excluded.

No comparison of contamination level with previous studies could be performed (as for copepods), since, to the best of our knowledge, this is the first study investigating PAH and PCB occurrence in Hyperbenthic Isopoda.

\subsubsection{Ichthyoplankton}

Finally, the PAH and PCB occurrence was also determined for the fourth taxon, fish larvae (ichthyoplankton). Results revealed, regarding PAHs, only $\mathrm{NaPh}$ and AcPy were detected, with concentrations below quantitation limits, while PCB congeners were not detected.

Comparing to previous taxa, ichthyoplankton showed the lowest contamination; such behavior could be ascribed to fish larvae feeding habits. Indeed, ichthyoplankton feeding is typically based on copepods larvae that are characterized by a short lifetime and, hence, a short exposure to pollution agents dissolved in water. The transfer of pollutants is, therefore, further hindered.

Finally, it should be mentioned that PAH concentrations detected in the four target taxa did not exceed regulation limits $(5 \mu \mathrm{g} / \mathrm{Kg}$ of $\mathrm{BaP})$.

\subsection{Bioaccumulation Factors}

The BAF (Bioaccumulation Factor) represents one of the most used models to predict the partitioning between an exposure medium (such as seawater) and biota [57]. Two possible mechanisms could influence the bioaccumulation of copepods (and hence the BAF values), namely the ingestion of contaminated dietary sources and the diffusive sorption of pollutants from water [58].

In the present study, BAF values were calculated for the PAH congeners detected both in seawater and in copepods ( $\mathrm{NaPh}, \mathrm{AcPY}, \mathrm{Flu}, \mathrm{Phe}, \mathrm{Ant}, \mathrm{FlTh}$ and BkFl). To evaluate a possible effect of feeding habits in the bioaccumulation, BAF values were calculated for herbivorous and carnivorous copepods. PCBs were not included since they were seldom detected in all the sea compartments investigated. The logarithms of BAF values are summarized in Table 1. 
Table 1. Logarithmic Bioaccumulation Factors (BAF) from seawater calculated for both herbivorous and carnivorous copepods.

\begin{tabular}{ccc}
\hline & $\begin{array}{c}\operatorname{LogBAF}_{\text {Herb }} \\
{[\mathbf{L} / \mathbf{K g}]}\end{array}$ & $\begin{array}{c}\text { LogBAF } \\
{[\mathbf{L} / \mathbf{K g}]}\end{array}$ \\
\hline $\mathrm{NaPh}$ & 2.50 & 2.88 \\
$\mathrm{AcPY}$ & 2.64 & 2.92 \\
$\mathrm{Flu}$ & 2.83 & 3.30 \\
Phe & 2.81 & 3.30 \\
Ant & 2.82 & 3.36 \\
FlTh & 2.90 & 3.59 \\
BkFl & 3.19 & 3.79 \\
Taxon average & 2.81 & 3.31 \\
\hline
\end{tabular}

The $\log$ BAFs obtained revealed positive values for both herbivorous and carnivorous copepods, thus highlighting that, for both taxa, a bioaccumulation from seawater occurred. Average values, 2.8 and 3.4 for herbivorous and carnivorous copepods, respectively, are in good agreement with those discovered by Arias et al. in Pseudodiaptomus marinus copepods [59].

LogBAF average values of herbivores and carnivores were shown to be statistically different (t-test, $\mathrm{N}=7, p=0.001$ ), meaning that higher values observed for carnivorous copepods corresponded to a higher bioaccumulation. Even if it is not possible to univocally explain this behavior, this higher value could represent a first biomagnification effect, since carnivorous copepods feed mainly on herbivorous ones. Hence, an increase of pollutant concentrations along the trophic chain is not unexpected.

The plotting of $\log$ BAFs against $\operatorname{logKow}$ (Figure 4) exhibited a sound correlation for both taxa ( $R^{2}=0.92$ for herbivorous and $R^{2}=0.81$ for carnivorous), supporting the hypothesis that the lipophilicity of the molecule provides the main factor driving the type of PAH congeners in copepods.

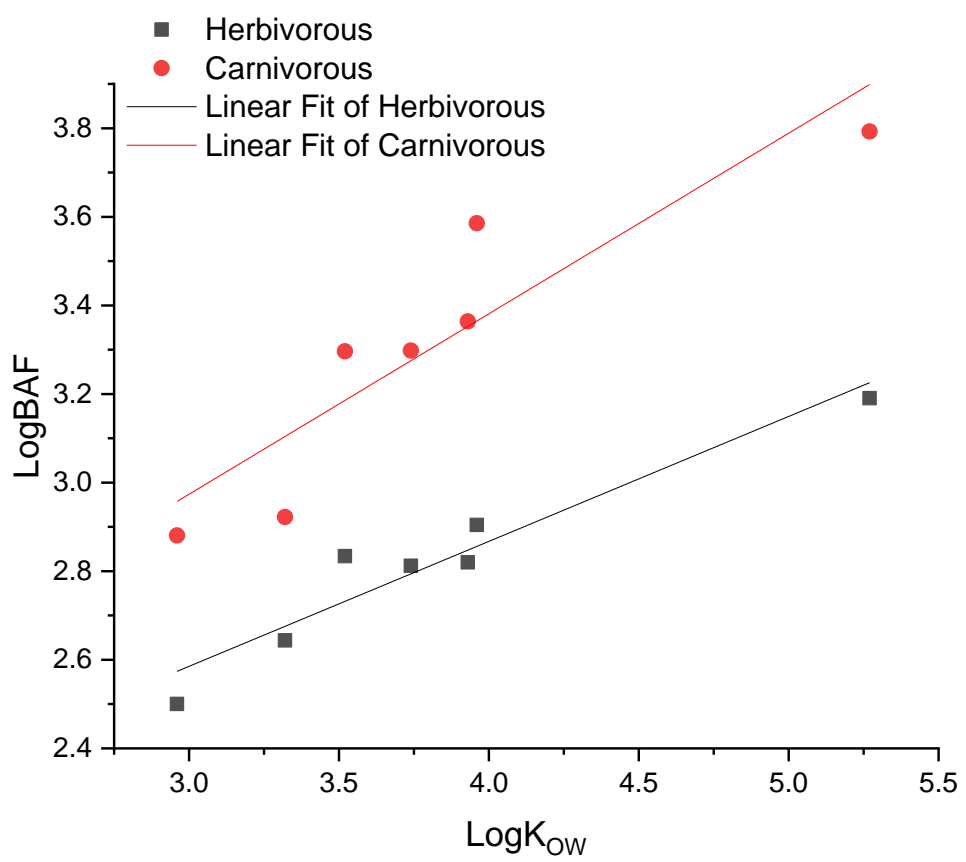

Figure 4. Linear modelling of LogBAFs against LogKow of PAHs for both herbivorous (black squared symbols) and carnivorous (red circled symbols) copepods. 


\section{Conclusions}

This work represents the first study devoted to the comprehensive investigation of 16 PAHs and 14 PCBs (including dioxin-like congeners) in the seawater, sediment and biota of the Ligurian Sea.

For both PAHs and PCBs, the overall results indicate that the contamination levels are equivalent to those typically found in other areas of the Mediterranean Sea characterized by moderate to high pollution. Moreover, this study reveals that PAHs origin is mainly ascribed to pyrogenic activities (combustion, transport, etc). A seasonal trend was observed for the presence of PAHs and PCBs in seawater, since micropollutant concentrations measured in summer were higher than those measured in winter, in agreement with increased touristic and harbor activities and with the higher stratification of water layers.

Micropollutant partition between water and sediment was confirmed to be influenced by the hydrophobicity of the pollutant molecules. To elucidate, higher molecular weight pollutants were preferentially detected in sediment, with organic matter acting as adsorbent. Bioaccumulation on biota was also assessed for copepods.

In addition, partition pathways were investigated within four different taxa (hyperbenthic Isopoda, herbivores and carnivorous holoplanktonic crustaceans copepods and fish larvae-ichthyoplankton), by the calculation of BAF values. The effects of living habits were shown to strongly influence bioaccumulation, as the congeners detected in sediment were preferentially discovered in taxa that spent most of their lives there. Moreover, feeding habits were found to influence the bioaccumulation of PAHs and PCBs, and a positive correlation between BAF values and hydrophobicity was confirmed. This study performed in the Southern Ligurian Sea, provides a novel insight into PAH and PCB distribution in marine zooplankton, which represents the main food constituent of most fish of the coastal waters, thus playing an important role in the transfer of pollutants through the food web. The experimental approach here followed can be transposed to other geographical areas of strategic importance to understand peculiar distributions patterns.

Supplementary Materials: The following supporting information can be downloaded at: https:/ / www.mdpi.com/article/10.3390/app12052564/s1, Figure S1. Ligurian Sea (Western Mediterranean): study area and location of sampling stations; Figure S2: average $(n=3) \mathrm{PAH}$ and PCB recoveries from seawater samples. Recoveries were calculated using surrogates as described in the Materials and Methods Section; Figure S3: average $(n=3)$ PAH and PCB recoveries from sediment samples. Recoveries were calculated using surrogates as described in the Materials and Methods Section; Figure S4: average $(n=3)$ PAH and PCB recoveries from biota samples. Recoveries were calculated using surrogates as described in the Materials and Methods Section; Table S1: MDL and MQL of PAHs in seawater, sediment and biota, using optimized analytical protocols, compared with their regulation limits reported by 2013/39/EU normative and Italian Legislative Decree 172/2015; Table S2: MDL and MQL of PCBs in seawater, sediment and biota, using optimized analytical protocols, compared with their regulation limits reported by 2013/39/EU normative and Italian Legislative Decree 172/2015.

Author Contributions: Conceptualization, L.R., M.C., N.N. and M.C.B.; Formal analysis, M.C.; Funding acquisition, M.C.B.; Investigation, L.R., N.N., M.B., R.M.S. and M.C.B.; Methodology, L.R., M.C., N.N. and M.C.B.; Project administration, M.C.B.; Supervision, M.C.B.; Validation, L.R. and M.C.; Visualization, M.B., L.F. and M.C.B.; Writing—original draft, L.R.; Writing—review and editing, L.R., N.N., R.M.S. and M.C.B. All authors have read and agreed to the published version of the manuscript.

Funding: This research was funded by Ministero dell'Università e della Ricerca, Ex60\%.

Institutional Review Board Statement: Not applicable.

Informed Consent Statement: Not applicable.

Data Availability Statement: Not applicable.

Acknowledgments: The authors would like to thank Andrea Dalla Libera and Lamberto Giusti for their kind assistance in laboratory experiments. Financial support from Ministero della Ricerca e dell'Università (Ex-60\%) is gratefully acknowledged. 
Conflicts of Interest: The authors declare no conflict of interest.

\section{References}

1. Kumar, S. Modern Treatment Strategies for Marine Pollution; Elsevier: Amsterdam, The Netherlands, 2020.

2. Simeonov, L.I.; Macaev, F.Z.; Simeonova, B.G. Environmental Security Assessment and Management of Obsolete Pesticides in Southeast Europe; Springer: Berlin/Heidelberg, Germany, 2014.

3. Steinberg, D.K.; Landry, M.R. Zooplankton and the ocean carbon cycle. Annu. Rev. Mar. Sci. 2017, 9, 413-444. [CrossRef] [PubMed]

4. Vikas, M.; Dwarakish, G. Coastal pollution: A review. Aquat. Procedia 2015, 4, 381-388. [CrossRef]

5. Battuello, M.; Brizio, P.; Sartor, R.M.; Nurra, N.; Pessani, D.; Abete, M.; Squadrone, S. Zooplankton from a North Western Mediterranean area as a model of metal transfer in a marine environment. Ecol. Indic. 2016, 66, 440-451. [CrossRef]

6. Vernberg, J.F. Physiological Responses of Marine Biota to Pollutants; Elsevier: Amsterdam, The Netherlands, 2012.

7. Wakeham, S.G.; McNichol, A.P. Transfer of organic carbon through marine water columns to sediments-insights from stable and radiocarbon isotopes of lipid biomarkers. Biogeosciences 2014, 11, 6895-6914. [CrossRef]

8. Nematollahi, M.J.; Keshavarzi, B.; Moore, F.; Vogt, R.D.; Nasrollahzadeh Saravi, H. Trace elements in the shoreline and seabed sediments of the southern Caspian Sea: Investigation of contamination level, distribution, ecological and human health risks, and elemental partition coefficient. Environ. Sci. Pollut. Res. 2021, 28, 1-24. [CrossRef]

9. Cheng, J.; Han, J.; Zheng, B.; Wang, X.; Yang, Z.; Zhang, X. Exploring the influence of water exchange on the distribution of polycyclic aromatic hydrocarbons in marine sediments by numerical calculation model. J. Hydrol. 2021, 603, 126874. [CrossRef]

10. Alshemmari, H. An overview of persistent organic pollutants along the coastal environment of Kuwait. Open Chem. 2021, 19, 149-156. [CrossRef]

11. Gioia, R.; Dachs, J.; Nizzetto, L.; Berrojalbiz, N.; Galbán, C.; Del Vento, S.; Méjanelle, L.; Jones, K.C. Sources, transport and fate of organic pollutants in the oceanic environment. In Persistent Pollution-Past, Present and Future; Springer: Berlin/Heidelberg, Germany, 2011; pp. 111-139.

12. Lawson, M.C.; Cullen, J.A.; Nunnally, C.C.; Rowe, G.T.; Hala, D.N. PAH and PCB body-burdens in epibenthic deep-sea invertebrates from the northern Gulf of Mexico. Mar. Pollut. Bull. 2021, 162, 111825. [CrossRef]

13. Sprovieri, M.; Feo, M.L.; Prevedello, L.; Manta, D.S.; Sammartino, S.; Tamburrino, S.; Marsella, E. Heavy metals, polycyclic aromatic hydrocarbons and polychlorinated biphenyls in surface sediments of the Naples harbour (southern Italy). Chemosphere 2007, 67, 998-1009. [CrossRef]

14. Moon, H.-B.; Yoon, S.-P.; Jung, R.-H.; Choi, M. Wastewater treatment plants (WWTPs) as a source of sediment contamination by toxic organic pollutants and fecal sterols in a semi-enclosed bay in Korea. Chemosphere 2008, 73, 880-889. [CrossRef]

15. Foster, G.D.; Cui, V. PAHs and PCBs deposited in surficial sediments along a rural to urban transect in a Mid-Atlantic coastal river basin (USA). J. Environ. Sci. Health Part A 2008, 43, 1333-1345. [CrossRef] [PubMed]

16. Golomb, D.; Barry, E.; Fisher, G.; Varanusupakul, P.; Koleda, M.; Rooney, T. Atmospheric deposition of polycyclic aromatic hydrocarbons near New England coastal waters. Atmos. Environ. 2001, 35, 6245-6258. [CrossRef]

17. Nakata, H.; Sakai, Y.; Miyawaki, T.; Takemura, A. Bioaccumulation and toxic potencies of polychlorinated biphenyls and polycyclic aromatic hydrocarbons in tidal flat and coastal ecosystems of the Ariake Sea, Japan. Environ. Sci. Technol. 2003, 37, 3513-3521. [CrossRef] [PubMed]

18. Bruzzoniti, M.C.; Rivoira, L.; Castiglioni, M.; El Ghadraoui, A.; Ahmali, A.; El Mansour, T.E.H.; Mandi, L.; Ouazzani, N.; Del Bubba, M. Extraction of polycyclic aromatic hydrocarbons and polychlorinated biphenyls from urban and olive mill wastewaters intended for reuse in agricultural irrigation. J. AOAC Int. 2020, 103, 382-391. [CrossRef] [PubMed]

19. Rivoira, L.; Castiglioni, M.; Kettab, A.; Ouazzani, N.; Al-Karablieh, E.; Boujelben, N.; Fibbi, D.; Coppini, E.; Giordani, E.; Del Bubba, M. Impact of effluents from wastewater treatments reused for irrigation: Strawberry as case study. Environ. Eng. Manag. J. 2019, 18, 2133-2143.

20. Cardellicchio, N.; Buccolieri, A.; Giandomenico, S.; Lerario, V.L.; Lopez, L.; Pizzulli, F. Distribution and occurence of polycyclic aromatic hydrocarbons (PAHs) in sediments from the Mar Grande and Gulf of Taranto (Ionian Sea, Southern Italy). Ann. Chim. J. Anal. Environ. Cult. Herit. Chem. 2006, 96, 51-64. [CrossRef]

21. ChemAxon. Chemicalize. Available online: https://chemicalize.com/ (accessed on 29 December 2021).

22. European Parliament and Council. Directive 2013/39/EU as Regards Priority Substances in the Field of Water Policy; European Parliament and Council: Strasbourg, France, 2013.

23. Repubblica Italiana. DECRETO LEGISLATIVO 13 Ottobre 2015, n. 172 Sulle Sostanze Prioritarie Nel Settore della Politica delle Acque; Gazzetta Ufficiale: Rome, Italy, 2015.

24. Ma, M.; Feng, Z.; Guan, C.; Ma, Y.; Xu, H.; Li, H. DDT, PAH and PCB in sediments from the intertidal zone of the Bohai Sea and the Yellow Sea. Mar. Pollut. Bull. 2001, 42, 132-136. [CrossRef]

25. Sinaei, M.; Mashinchian, A. Polycyclic aromatic hydrocarbons in the coastal sea water, the surface sediment and Mudskipper Boleophthalmus dussumieri from coastal areas of the Persian Gulf: Source investigation, composition pattern and spatial distribution. J. Environ. Health Sci. Eng. 2014, 12, 1-11. [CrossRef]

26. Sobek, A.; Reigstad, M.; Gustafsson, Ö. Partitioning of polychlorinated biphenyls between Arctic seawater and size-fractionated zooplankton. Environ. Toxicol. Chem. Int. J. 2006, 25, 1720-1728. [CrossRef] 
27. Pizzini, S.; Morabito, E.; Gregoris, E.; Vecchiato, M.; Corami, F.; Piazza, R.; Gambaro, A. Occurrence and source apportionment of organic pollutants in deep sediment cores of the Venice Lagoon. Mar. Pollut. Bull. 2021, 164, 112053. [CrossRef]

28. Pitacco, V.; Mistri, M.; Granata, T.; Moruzzi, L.; Maria, L.M.; Massara, F.; Sfriso, A.; Sfriso, A.A.; Munari, C. Sediment Contamination by Heavy Metals and PAH in the Piombino Channel (Tyrrhenian Sea). Water 2021, 13, 1487.

29. Cardellicchio, N.; Annicchiarico, C.; Di Leo, A.; Giandomenico, S.; Spada, L. The Mar Piccolo of Taranto: An interesting marine ecosystem for the environmental problems studies. Environ. Sci. Pollut. Res. 2016, 23, 12495-12501. [CrossRef] [PubMed]

30. Bertolotto, R.; Ghioni, F.; Frignani, M.; Alvarado-Aguilar, D.; Bellucci, L.; Cuneo, C.; Picca, M.; Gollo, E. Polycyclic aromatic hydrocarbons in surficial coastal sediments of the Ligurian Sea. Mar. Pollut. Bull. 2003, 46, 907-913. [CrossRef]

31. Deyme, R.; Bouloubassi, I.; Taphanel-Valt, M.-H.; Miquel, J.-C.; Lorre, A.; Marty, J.-C.; Mejanelle, L. Vertical fluxes of organic contaminants in the Ligurian Sea. In Proceedings of the EGU General Assembly Conference Abstracts, Vienna, Austria, 2-7 May 2010; p. 9955.

32. Pane, L.; Boccardo, S.; Bonfiglioli, F.; Mariottini, G.L.; Priano, F.; Conio, O. Polycyclic aromatic hydrocarbons in water, seston and copepods in a harbour area in the Western Mediterranean (Ligurian Sea). Mar. Ecol. 2005, 26, 89-99. [CrossRef]

33. Gobas, F.; Morrison, H.A. Bioconcentration and biomagnification in the aquatic environment. In Handbook of Property Estimation Methods for Chemicals; CRC Press: Boca Raton, FL, USA, 2000; pp. 189-231.

34. Albarano, L.; Zupo, V.; Caramiello, D.; Toscanesi, M.; Trifuoggi, M.; Guida, M.; Libralato, G.; Costantini, M. Sub-Chronic Effects of Slight PAH-and PCB-Contaminated Mesocosms in Paracentrotus lividus Lmk: A Multi-Endpoint Approach and De Novo Transcriptomic. Int. J. Mol. Sci. 2021, 22, 6674. [CrossRef]

35. Li, Q.; Xu, X.; Sen-Chun, L.F.; Wang, X. Determination of trace PAHs in seawater and sediment pore-water by solid-phase microextraction (SPME) coupled with GC/MS. Sci. China Ser. B Chem. 2006, 49, 481-491. [CrossRef]

36. Leppäranta, M.; Myrberg, K. Physical Oceanography of the Baltic Sea; Springer Science \& Business Media: Berlin/Heidelberg, Germany, 2009.

37. Fabbri, E.; Franzellitti, S. Human pharmaceuticals in the marine environment: Focus on exposure and biological effects in animal species. Environ. Toxicol. Chem. 2016, 35, 799-812. [CrossRef]

38. Bourg, N.; Molcard, A. Northern boundary current variability and mesoscale dynamics: A long-term HF RADAR monitoring in the North-Western Mediterranean Sea. Ocean. Dyn. 2021, 71, 851-870. [CrossRef]

39. Rice, S.D.; Holland, L.; Moles, A. Seasonal increases in polycyclic aromatic hydrocarbons related to two-stroke engine use in a small Alaskan lake. Lake Reserv. Manag. 2008, 24, 10-17. [CrossRef]

40. Ali, H.R.; Nour, S.; El-Ezbewy, S.; El-gemaee, G.H.; Moustafa, Y.; Roushdy, M. Assessment of polycyclic aromatic hydrocarbons contamination in water, sediment and fish of Temsah Lake, Suez Canal, Egypt. Curr. World Environ. 2006, 1, 11-22. [CrossRef]

41. Magi, E.; Bianco, R.; Ianni, C.; Di Carro, M. Distribution of polycyclic aromatic hydrocarbons in the sediments of the Adriatic Sea. Environ. Pollut. 2002, 119, 91-98. [CrossRef]

42. Tolosa, I.; de Mora, S.; Sheikholeslami, M.R.; Villeneuve, J.-P.; Bartocci, J.; Cattini, C. Aliphatic and aromatic hydrocarbons in coastal Caspian Sea sediments. Mar. Pollut. Bull. 2004, 48, 44-60. [CrossRef]

43. Odabasi, M.; Dumanoglu, Y.; Kara, M.; Altiok, H.; Elbir, T.; Bayram, A. Spatial variation of PAHs and PCBs in coastal air, seawater and sediments in a heavily industrialized region. Environ. Sci. Pollut. Res. 2017, 24, 13749-13759. [CrossRef] [PubMed]

44. Baumard, P.; Budzinski, H.; Garrigues, P. Polycyclic aromatic hydrocarbons in sediments and mussels of the western Mediterranean Sea. Environ. Toxicol. Chem. Int. J. 1998, 17, 765-776. [CrossRef]

45. Guigue, C.; Tedetti, M.; Dang, D.H.; Mullot, J.-U.; Garnier, C.; Goutx, M. Remobilization of polycyclic aromatic hydrocarbons and organic matter in seawater during sediment resuspension experiments from a polluted coastal environment: Insights from Toulon Bay (France). Environ. Pollut. 2017, 229, 627-638. [CrossRef]

46. Komada, T.; Schofield, O.M.; Reimers, C.E. Fluorescence characteristics of organic matter released from coastal sediments during resuspension. Mar. Chem. 2002, 79, 81-97. [CrossRef]

47. Iwata, H.; Tanabe, S.; Aramoto, M.; Sakai, N.; Tatsukawa, R. Persistent organochlorine residues in sediments from the Chukchi Sea, Bering Sea and Gulf of Alaska. Mar. Pollut. Bull. 1994, 28, 746-753. [CrossRef]

48. Jafarabadi, A.R.; Bakhtiari, A.R.; Mitra, S.; Maisano, M.; Cappello, T.; Jadot, C. First polychlorinated biphenyls (PCBs) monitoring in seawater, surface sediments and marine fish communities of the Persian Gulf: Distribution, levels, congener profile and health risk assessment. Environ. Pollut. 2019, 253, 78-88. [CrossRef]

49. Barakat, A.O.; Mostafa, A.; Wade, T.L.; Sweet, S.T.; El Sayed, N.B. Distribution and characteristics of PAHs in sediments from the Mediterranean coastal environment of Egypt. Mar. Pollut. Bull. 2011, 62, 1969-1978. [CrossRef]

50. Cailleaud, K.; Forget-Leray, J.; Souissi, S.; Hilde, D.; LeMenach, K.; Budzinski, H. Seasonal variations of hydrophobic organic contaminant concentrations in the water-column of the Seine Estuary and their transfer to a planktonic species Eurytemora affinis (Calanoida, copepoda). Part 1: PCBs and PAHs. Chemosphere 2007, 70, 270-280. [CrossRef]

51. Tiano, M.; Tronczyński, J.; Harmelin-Vivien, M.; Tixier, C.; Carlotti, F. PCB concentrations in plankton size classes, a temporal study in Marseille Bay, Western Mediterranean Sea. Mar. Pollut. Bull. 2014, 89, 331-339. [CrossRef] [PubMed]

52. Kiørboe, T. What makes pelagic copepods so successful? J. Plankton Res. 2011, 33, 677-685. [CrossRef]

53. Cole, M.; Lindeque, P.; Fileman, E.; Halsband, C.; Goodhead, R.; Moger, J.; Galloway, T.S. Microplastic ingestion by zooplankton. Environ. Sci. Technol. 2013, 47, 6646-6655. [CrossRef] [PubMed] 
54. Johnson, W.S.; Allen, D.M. Zooplankton of the Atlantic and Gulf Coasts: A Guide to Their Identification and Ecology; JHU Press: Baltimore, MA, USA, 2012.

55. Rivoira, L.; Castiglioni, M.; Rodrigues, S.; Freitas, V.; Bruzzoniti, M.; Ramos, S.; Almeida, C. Microplastic in marine environment: Reworking and optimisation of two analytical protocols for the extraction of microplastics from sediments and oysters. MethodsX 2020, 7, 101116. [CrossRef]

56. Koulouri, P. Preliminary study of hyperbenthos in Heraklion Bay (Cretan Sea). Biomare Newsl. 2002, 3, 12.

57. Newman, M.C. Quantitative Methods in Aquatic Ecotoxicology; CRC Press: Boca Raton, FL, USA, 1994.

58. Berrojalbiz, N.; Lacorte, S.; Calbet, A.; Saiz, E.; Barata, C.; Dachs, J. Accumulation and cycling of polycyclic aromatic hydrocarbons in zooplankton. Environ. Sci. Technol. 2009, 43, 2295-2301. [CrossRef]

59. Arias, A.H.; Souissi, A.; Roussin, M.; Ouddane, B.; Souissi, S. Bioaccumulation of PAHs in marine zooplankton: An experimental study in the copepod Pseudodiaptomus marinus. Environ. Earth Sci. 2016, 75, 1-9. [CrossRef] 